\title{
DIAGNÓSTICO DAS BIBLIOTECAS ESCOLARES \\ DA REDE ESTADUAL DE ENSINO DO \\ MUNICÍPIO dE SÃO CARLOS
}

\section{Elisabeth Marcia Martucci \\ Maria Regina Milani}

\begin{abstract}
Resumo
Caracterização das bibliotecas das escolas estaduais de 1o. e de 2o. graus do Município de São Carlos em relação aos seus recursos físicos, materiais e humanos, acervos documentais, serviços prestados e comunidade de usuários. A partir de uma pesquisa-diagnóstico informações foram levantadas sobre os itens supracitados.
\end{abstract}

Palavras-chave

Biblioteca escolar - Ensino público estadual de 1o.e 2o. graus - São Carlos - Estado de São Paulo

\section{A BIBLIOTECA ESCOLAR}

Para a conceituação de biblioteca escolar toma-se como referencial documento de cunho regional, produzido por diversos países da América Latina, sob os auspícios da Organização dos Estados Americanos, pela participação no Projeto Multinacional de Bibliotecas Escolares (OEA, 1985).

Tal opção é justificada pela similaridade nas características de desenvolvimento dos países, assim como pela existência de pontos coincidentes no desenvolvimento das bibliotecas escolares na América Latina: tendência de projetos-piloto, organização de redes geográficas, capacitação do professor bibliotecário, problemas or- çamentários e falta de apoio institucional.

Outra justificativa é que o país não possui delineada uma política nacional de bibliotecas escolares, estando esta temática sob a responsabilidade dos sistemas estaduais de ensino, o que resulta num panorama heterogêneo de políticas oficiais estaduais e diferenciações significativas entre os estados federados.

A biblioteca escolar é considerada como um centro ativo de aprendizagem, possuindo um duplo sentido: "é ao mesmo tempo, um elemento de conservação e um centro de comunicação" (Ibid, p.19), mas o conceito moderno atualiza a função de comunicação, como suporte informacional da instituição educativa. Seu conceito expresso é: 
"A biblioteca escolar é uma instituição do sistema social que organiza materiais bibliográficos, audiovisuais e outros meios e os coloca à disposição de uma comunidade educacional.Constitui parte integral do sistema educacional e participa de seus objetivos, metas e fins. A biblioteca escolar é um instrumento de desenvolvimento do currículo e permite o fomento da leitura e da formação de uma atitude científica; constitui um elemento que forma o indivíduo para a aprendizagem permanente; estimula a criatividade, a comunicação, facilita a recreação, apoia os docentes em sua capacitação e lhes oferece a informação necessária para a tomada de decisões na aula.Trabalha também com os pais de família e com outros agentes da comunidade." (Ibid, p.22)

Tomé (apud OEA, p.21) conceitua biblioteca escolar como:

"um centro ativo de aprendizagem com uma participação direta em todos os aspectos do programa de educação com materiais de todo tipo, onde educadores, estudantes e usuários em geral podem redescobrir e ampliar os conhecimentos, desenvolver pesquisas, desenvolver aptidões para a leitura, para opinar, para avaliar, assim como desenvolver todos os meios de comunicação que dispõe o ser humano com o objetivo de assegurar uma aprendizagem total já que vivemos em um mundo multidimensional que nos exige uma reação multidimensional."

De tais conceitos pode-se extrair elementos chaves e comuns a toda biblioteca escolar: uma variada coleção de materiais bibliográficos; uma organização destes materiais que permita seu manuseio; um elemento humano que responda à organização, manutenção e prestação de serviço, em função do desenvolvimento do currículo e dos objetivos da educação; um espaço que permita armazenar estes materiais e organizar situações favoráveis à aprendizagem; um elenco de atividades que levem ao cumprimento dos objetivos definidos em relação com o currículo, a leitura, a aprendizagem permanente; e usuários provenientes da comunidade educativa.

Nesta perspectiva conceitual seus objetivos são expressos em relação a vários aspectos :

1. em relação ao sistema educacional, deve contribuir para o cumprimento das políticas nacionais, para o alcance de metas qualitativas da educação e para a democratização do acesso e uso da informação;

2. em função do processo de ensinoaprendizagem, deve criar e manter um ambiente educacional rico, variado e dinâmico que contribua para o desenvolvimento de um currículo ativo e flexível;

3. em relação à leitura, deve contribuir para o desenvolvimento de experiências que estimulem a leitura como fonte de informação e prazer e com isso formar o leitor autônomo, crítico e criativo;

4. em relação à criação de uma atitude científica, deve oferecer um contexto estimulante que favoreça a descoberta, o desenvolvimento e o intercâmbio de experiências, que propiciem a formação do espírito investigador;

5. em relação à aprendizagem permanente, deve 
formar e desenvolver no aluno e no professor habilidades de busca, análise, uso e criação da informação que facilitem a aprendizagem permanente;

6. quanto ao desenvolvimento da criatividade, deve estimular a imaginação e o desenvolvimento de habilidades criativas e o sentido estético, integrando áreas científicas, técnicas e artísticas;

7. em relação à comunicação, deve desenvolver habilidades de comunicação e expressão, através da manipulação de variados materiais, equipamentos, meios de comunicação e suas linguagens;

8. em relação à recreação, deve oferecer a oportunidade de uso do tempo livre para a prática da leitura prazerosa e de atividades recreativas derivadas da mesma;

9. em relação à capacitação de professores, deve apoiar os sistemas de formação, capacitação e aperfeiçoamento dos professores e oferecer mecanismos que permitam desenvolver de forma permanente e eficiente a capacitação dos professores;

10. em relação à informação científica, deve facilitar o acesso do professor à informação científica e tecnológica;

11. em relação à comunidade, deve contribuir para o desenvolvimento de programas de educação de adultos e educação não formal dentro de seu raio de ação, contribuir nas campanhas de alfabetização, desenvolver atividades de desenvolvimento cultural, em uma concepção ampla da relação entre escola e comunidade.

Podem-se também abordar os objetivos da biblioteca por faixa de escolaridade dos usuários, como fazem Macedo \& Siqueira (1987, p.69), no sentido de enfatizar o recorte predominante de atuação no processo de escolarização.

\section{Em se tratando de}

- usuários de pré-escola a 3a. série - fase anterior à alfabetização, alfabetização e sistematização, a biblioteca escolar objetiva o desenvolvimento de habilidades artísticas, a estimulação da percepção e da criatividade e o incentivo à leitura através de textos com predominância de imagens em relação ao texto, proporcionando o prazer de ler;

\section{Ao passo que no caso de}

- usuários de 4a. a 8a. série, 2o. grau, professores e outros - a biblioteca escolar objetiva, sobretudo, secundar as atividades de apoio ao estudo e à pesquisa, capacitando os alunos, professores e demais usuários a utilizarem, de maneira eficiente, os recursos informacionais na obtenção de informação.

A formação e o desenvolvimento da coleção constitui uma atividade diversa da avaliação e seleção de materiais, devendo levar em consideração os programas curriculares, os níveis de leitura dos alunos, os interesses e necessidades da comunidade usuária e os recursos disponíveis. 
A coleção da biblioteca escolar é abordada como recursos informacionais variados e atualizados, incluindo os materiais necessários para cumprir suas funções, sendo enumerados os materiais bibliográficos e os não-bibliográficos. Na categoria de materiais bibliográficos são incluídos todos os materiais impressos, livros, publicações periódicas, folhetos. Mas, são destacadas as seguintes tipologias: a literatura infantil e juvenil, as obras de consulta e referência e os livros de textos ou manuais escolares, numa perspectiva ampla de classificação, na medida em que cada material pode ser usado para finalidades diversificadas. Na tipologia de materiais não bibliográficos, são incluídos os materiais audiovisuais, sonoros, jogos, materiais de sucata, globos, caixas e todo tipo de material diferente do impresso.

Macedo \& Siqueira (loc. cit.) propõem a seguinte caracterização dos materiais: materiais bibliográficos (obras de referência, obras didáticas, bibliografias, revistas, jornais, recortes, mapas e ilustrações); materiais audiovisuais (discos, fitas, vídeos, filmes, transparências); materiais de animação cultural (tintas, pincéis, instrumentos musicais, fantoches, sucata, realia); materiais didáticos (globos, esqueletos, jogos didáticos, experimentotecas); equipamentos audiovisuais e outros.

A formação de coleções em bibliotecas escolares possui tentativas de estabelecimento de padrões. Por exemplo:

- a American Library Association (1952) estabelece que as bibliotecas escolares que possuem de 200 a 999 alunos devem possuir de 82
6.000 a 10.000 volumes e que aquelas com mais de 1.000 alunos devem possuir 10 volumes por aluno;

- a UNESCO recomenda que cada escola com mais de 200 alunos disponha, em média, de 10 livros por aluno em sua biblioteca (apud FDE, 1992);

- a IFLA - Federação Internacional de Associações de Bibliotecários e Bibliotecas (1991) recomenda, no mínimo, 5.000 títulos ou 10 volumes por aluno, o que for melhor. Mas, indica 20 títulos por estudante como meta para uma biblioteca escolar adequada aos anos 90;

- Sandroni (1986) indica como diretriz para a constituição de acervos de livros infantis e juvenis (ficção e não-ficção) um título por aluno, de acordo com o nível de leitura, a idade e a escolaridade, para leitura individual. Quanto à leitura coletiva, indica uma coleção de 30 exemplares por título e por turma.

A ambientação física também é tratada na literatura, e os seguintes aspectos são ressaltados: a área deve ser projetada com diversos ambientes, equipada e decorada para proporcionar um ambiente agradável e adequado ao pessoal, coleção e comunidade usuária; deve estar próxima das salas de aula, no andar térreo, com entrada independente, longe de lugar de muito ruído; deve ser bem iluminada e ventilada; deve proporcionar livre acesso às estantes e possuir um sistema de sinalização e orientação.

Carvalho (1972) cita que a American Association of School Libraries recomenda que Inf.Inf., Londrina, v. 4, n. 2, p. 78-94, jul./dez. 1999 
o espaço de leitura e estudo permita acomodar 45 a 55 leitores sentados, em escolas de 200 a 500 alunos e que em escolas maiores é necessário acomodações para $10 \%$ dos alunos, até o máximo de 80 a 100 cadeiras. Para escolas menores, com menos de 200 alunos, é suficiente acomodar uma classe escolar.

Os recursos humanos é que proporcionam a orientação e a coordenação das mudanças qualitativas que devem promover a biblioteca escolar, assim como conseguir a superação de deficiências dos demais componentes. São diversas as denominações dadas ao agente educacional em diversos países: bibliotecário-educador, bibliotecário-professor, bibliotecário escolar, bibliotecário este com formação e experiência em ambos os campos.

Na América Latina, o Brasil incluído, a falta de recursos humanos especializados aliada à política de contratação de pessoal de apoio pedagógico ou de especialistas em educação, tem deslocado para a biblioteca escolar o professor bibliotecário, que possui a formação básica como professor, uma experiência no mesmo sentido e uma capacitação introdutória em Biblioteconomia. Ao profissional bibliotecário fica a responsabilidade de planejamento, implantação, acompanhamento e avaliação dos serviços estruturados em redes e sistemas.

No Brasil, vários indicadores apontam para um quadro pessimista de implantação, desenvolvimento e atuação das bibliotecas escolares, expressando sua precariedade de condições: falta de espaço físico adequado, de mobiliário e equipamentos, falta de política de desenvolvimento de coleções, falta de pessoal em número e qualificação, falta de programas de capacitação de pessoal. Silva (1995) chega a afirmar que a "biblioteca escolar brasileira encontra-se sob o mais profundo silêncio; silenciam as autoridades, ignoram-na os pesquisadores, calam-se os professores, omitem-se os bibliotecários".

Para não seguir esta direção, o projeto de pesquisa "Diagnóstico da Rede Escolar de PréEscola, 1o. e 2o. Graus localizada no Município de São Carlos”, financiado pelo Programa de Fomento à Extensão Universitária do Ministério da Educação e do Desporto incluiu a biblioteca escolar como um de seus subprojetos. O projeto de pesquisa de caráter diagnóstico envolveu vários departamentos e docentes da Universidade Federal de São Carlos com o objetivo de definir a rede escolar em relação à sua estrutura física, administrativa e pedagógica, aos recursos materiais e equipamentos, ao corpo docente, discente e técnico-administrativo, aos órgãos superiores e à comunidade, à demanda e oferta de vagas e à evasão e retenção escolar.

\section{OBJETIVOS}

O subprojeto "Diagnóstico das Bibliotecas Escolares da Rede Estadual de Ensino do Município de São Carlos" teve como objetivo geral : diagnosticar as bibliotecas escolares da rede estadual de ensino do Município de São Carlos quanto ao seu funcionamento, recursos humanos, recursos informacionais, comunidade usuária, serviços e produtos oferecidos.

Seus objetivos específicos ficaram assim estabelecidos: 
- identificar a atividade regular, a desativação e a inexistência da biblioteca escolar;

- caracterizar os motivos da desativação ou fechamento da biblioteca escolar;

- caracterizar os motivos da inexistência da biblioteca escolar e os meios de atendimento das necessidades informacionais da comunidade educativa;

- identificar e caracterizar os recursos humanos alocados na biblioteca escolar em atividade regular, quanto ao número, formação, cargos ou funções contratuais, situação funcional e atividades de capacitação / treinamento realizadas;

- caracterizar os recursos físicos da biblioteca escolar quanto ao espaço físico ocupado e ambiências existentes, condições de ventilação, iluminação e segurança;

- identificar e caracterizar o mobiliário disponível para usuários, funcionários, serviços e armazenamento do acervo;

- identificar os equipamentos existentes na biblioteca escolar;

- caracterizar a comunidade usuária da biblioteca escolar quanto à tipologia, acesso ao acervo e freqüência de uso;

- identificar a responsabilidade, os instrumentos e os critérios adotados para a seleção dos materiais;

- identificar as tipologias adotadas para a aquisição dos materiais, assim como a proveniência dos recursos financeiros;

- identificar e caracterizar as metodologias já implementadas para a avaliação da coleção;

- identificar e caracterizar o acervo da biblioteca, por tipologias documentais;

- identificar os procedimentos genéricos de organização dos materiais;
- verificar o horário semanal de funcionamento da biblioteca, nos períodos de funcionamento da unidade escolar (matutino, vespertino e noturno);

- identificar os serviços de fornecimento de documentos e os serviços de alerta;

- identificar e caracterizar as atividades de incentivo à leitura e as atividades de animação cultural realizadas pela biblioteca escolar;

- identificar os meios formais e informais utilizados pela biblioteca escolar para a educação dos usuários.

\section{METODOLOGIA}

A população-alvo da pesquisa constituiu a totalidade das Escolas Estaduais de $1^{\circ}$. e $2^{\circ}$. Graus do Município de São Carlos, em número de 31 unidades escolares, subordinadas à Delegacia de Ensino Prof. João Elias Ferrari, de São Carlos.

O instrumento de coleta utilizado foi um questionário, dividido em 3 seções:

1) A Seção I - ficha cadastral da escola: foi destinada à caracterização da escola quanto ao seu nome, endereço completo e ao registro do nome do respondente e da data de preenchimento;

2) A Seção II - informação sobre a não-existência ou não atividade da biblioteca: foi destinada ao registro dos motivos da desativação ou inexistência da biblioteca escolar na unidade escolar e às formas de disponibilidade do material bibliográfico existente, além da caracterização de sua formação e uso; 
3) A Seção III - caracterização da biblioteca: foi preenchida pelas unidades escolares com biblioteca em regular funcionamento, constando de 5 blocos informacionais: Recursos Humanos, Recursos Físicos, Usuário, Acervo e Serviços e Produtos.

A Seção II foi composta de 5 questões fechadas e a Seção III de 35 questões fechadas, sendo seu preenchimento excludente, na dependência da situação da biblioteca escolar da unidade.

A coleta de dados ocorreu no 1o. semestre de 1995, especialmente nos meses de fevereiro e março, com o preenchimento do questionário pelo responsável pela biblioteca escolar. $\mathrm{Na}$ coleta de dados 3 unidades escolares deixaram de ser pesquisadas, pela ausência temporária dos responsáveis. Assim, o universo da pesquisa constou de 26 bibliotecas de escolas estaduais, distribuídas em 19 escolas de 1o. grau - EEPG, 6 escolas de 1o. e 2o. graus - EEPSG e 1 de 2o. grau - EESG.

\section{RESULTADOS}

Deste universo, 69.23\% possuía biblioteca escolar regular funcionando, ao passo que em $26.92 \%$ a biblioteca existia, mas encontrava-se desativada por algum motivo e em 3.85\% ela era inexistente. Tal situação indica que, na maioria das escolas estaduais, praticamente em $70 \%$ delas, a biblioteca escolar possui condições de funcionamento, mas em 30\% ela está desativada ou inexiste. A situação ideal seria o funcionamento regular da biblioteca escolar na totalidade do universo pesquisado, mas isto não ocorre por

\section{alguns motivos indicados.}

\subsection{BIBLIOTECAS DESATIVADAS}

A principal razão da desativação ou inexistência da biblioteca escolar é a falta de pessoal, sendo $87.50 \%$ as indicações nesse sentido.

Mas, outros motivos são citados revestindo-se de grande significação: $50 \%$ de respostas indicam a não-atualização do acervo e sua desorganização, $37.50 \%$ indicam a falta de mobiliário e equipamentos e $25 \%$ indicam a falta de espaço físico.

É importante ressaltar que apenas $12.50 \%$ das escolas com a biblioteca desativada indicaram apenas um motivo para esta desativação, as demais $87.50 \%$ indicaram de duas a quatro razões, parecendo haver uma relação entre elas, especialmente quanto à falta de pessoal e à desorganização das coleções.

Caberia à administração da unidade escolar a resolução dos problemas decorrentes da falta de espaço, de mobiliário, equipamentos e da política de desenvolvimento de coleções, para a obtenção de condições mínimas para o funcionamento da biblioteca escolar, mas a resolução da falta de pessoal enquadra-se num cenário mais amplo da política de recursos humanos do governo do Estado de São Paulo.

Pode-se afirmar que a carreira de bibliotecário, no quadro do funcionalismo público estadual da administração direta, é uma carreira em extinção, na medida em que desde o ano de 1974 não são admitidos novos profissionais para o preenchimento de cargos vagos por exoneração e 
aposentadorias, nem foram criados novos cargos na carreira.

A totalidade das escolas com biblioteca escolar desativada possui um acervo bibliográfico de apoio à disposição dos professores e alunos, mas por delimitação do instrumento de coleta de dados não fica claro onde está armazenado este material na unidade escolar.

Os meios de formação desses acervos bibliográficos são diversificados, consistindo de doações de professores $(87.50 \%)$, de alunos $(75 \%)$, de entidade estadual $(75 \%)$, de pessoas físicas (75\%) e de editores e livrarias (62.50\%). Pode-se inferir que a entidade estadual é a Fundação para o Desenvolvimento da Educação FDE, órgão da administração que, dentre suas muitas atribuições, tem a responsabilidade de implementar a leitura e as bibliotecas escolares da rede estadual de ensino, além de aquirir materiais bibliográficos e didáticos.

Estes resultados indicam que os acervos são formados e desenvolvidos de acordo com a capacidade da unidade escolar para obter doações, visto não dispor de recursos próprios para aquisições. Isso pode acarretar a formação de acervos não adequados às necessidades de informação educativa da comunidade escolar, se não for realizada uma seleção rigorosa no processo de incorporação dos itens bibliográficos doados.

O fato de a biblioteca estar desativada limita o uso de seu acervo bibliográfico pela comunidade escolar, na medida em que os documentos podem ser utilizados na sala de aula em todas as unidades pesquisadas ou são emprestados para uso na própria escola, em $75 \%$ das mesmas. Apenas em $37.50 \%$ delas é permitido o empréstimo domiciliar.

Por outro lado, o acervo também é utilizado pelos professores para realização da hora do conto e para dramatizações, com índices de 50\% e $37.50 \%$, respectivamente, talvez com o objetivo de incentivo à leitura.

\subsection{BIBLIOTECAS EM ATIVIDADE}

\subsubsection{Recursos Humanos}

Existem 29 profissionais em atividade nas bibliotecas escolares, com variação de 1 a 4 funcionários em cada uma, com média de 1.61 funcionário por unidade. O diagnóstico verifica que a maioria deles, $58,62 \%$, possuem formação superior ou de 3o. grau, aos quais se somam $3.45 \%$ com esta formação incompleta ou em curso. $27.59 \%$, tem o 2 o. grau completo, aos quais também se somam 3.45\% com esta formação incompleta ou em curso. Apenas $6.90 \%$ dos funcionários não têm a não ser o 1o. grau completo. Tal situação demonstra que os recursos humanos alocados nas bibliotecas escolares possuem formação educacional condizente com suas atribuições, pois praticamente $62 \%$ possuem formação superior universitária, o que parece indicar que a maioria são professores PIII. Esta situação funcional é verdadeira em relação aos responsáveis pelas bibliotecas escolares, indicando o percentual de 38.39 de Professores PIII. Desse índice referente ao Professor PIII, verificou-se o índice de $22.22 \%$ para os cargos de bibliotecário e funcio-

Inf.Inf., Londrina, v. 4, n. 2, p. 78-94, jul./dez. 1999 
nário de apoio, respectivamente. Com pouca incidência, aparecem os funcionários técnico-administrativos $(5.56 \%)$ e os professores PI $(11.11 \%)$.

De maneira geral, os dados indicam a presença maior de professores PIII como responsáveis das bibliotecas escolares, mas também com incidência significativa de bibliotecários e funcionários de apoio. Em relação aos professores PIII, é preciso lembrar que, na ocasião da coleta de dados, cada escola padrão desenvolvia o Projeto Centro de Informação e Criação - CIC, voltado para o desenvolvimento das bibliotecas escolares, que exigia o exercício de 20 horas semanais de um Professor PIII na biblioteca, como coordenador do projeto. Em relação aos bibliotecários, é preciso ressaltar que apenas 2, ou 50\% deles, são de fato funcionários de carreira da administração estadual; o restante parece estar exercendo sua atividade profissional na escola em decorrência de outros meios de contratação ou alocação. Vale também analisar que em $22.22 \%$ das unidades pesquisadas, por não existirem professores ou bibliotecários, os funcionários de apoio acabam sendo responsáveis pelas bibliotecas escolares.

Em relação à situação funcional dos responsáveis pelas bibliotecas escolares verificouse que apenas $22.22 \%$ deles estão em exercício regular do cargo/função exclusivamente na biblioteca. A maioria deles, $77.78 \%$, estão em outra situação: $38.89 \%$ dividem sua jornada de trabalho com a biblioteca; $11.11 \%$ estão em exercício regular de seu cargo/função, esporadicamente trabalhando na biblioteca e $27.78 \%$ trabalham na biblioteca por serem readaptados ou por não es- tarem em condições de saúde para o exercício regular de seu cargo ou função.

Tal diagnóstico é incisivo em demonstrar a dificuldade de alocação de recursos humanos na biblioteca escolar: ou é aproveitado um servidor readaptado (em geral, professor) ou algum funcionário ou professor desloca-se de suas funções normais para responsabilizar-se em tempo parcial pela biblioteca. Isso demonstra com clareza que a maioria das bibliotecas parecem não ter condições de um funcionamento regular, com abertura nos horários de funcionamento da unidade escolar.

Constatou-se que $83.33 \%$ dos responsáveis pelas bibliotecas escolares não receberam qualquer tipo de treinamento teórico e/ou prático, através da participação em cursos, palestras, seminários ou outros eventos promovidos por instituições públicas e privadas. Apenas 16.67\% anotaram ter participado de treinamentos.

Este resultado indica que, apesar do funcionamento da biblioteca escolar nas unidades, é possível questionar a qualidade da prestação de serviços de informação à comunidade, na medida em que podem inexistir requisitos prévios de conhecimento teórico e prático.

De maneira geral, percebe-se que a questão dos recursos humanos é um aspecto altamente problemático no funcionamento das bibliotecas escolares da rede estadual de ensino, o que também é indicado como motivo de desativação das mesmas. 


\subsubsection{Espaço Físico}

Em relação ao espaço físico, a situação é mais favorável ao funcionamento da biblioteca escolar, na medida em que em $88.89 \%$ das unidades existe uma sala para uso exclusivo da biblioteca. Apenas em 11.11\%, a sala da biblioteca é compartilhada com outras atividades: houve indicação de compartilhamento com a sala de inspetor de alunos e com a sala de vídeo.

As salas ocupadas pelas bibliotecas escolares possuem natureza diferenciada quanto ao seu planejamento: $33.38 \%$ constavam do projeto arquitetônico e estão sendo utilizadas como tal, ocupando outro espaço físico apenas 5,55\% delas. Em 38.89\% das escolas pesquisadas, porém, a biblioteca ocupa espaço adaptado, pois não constava do projeto de construção da unidade.

Neste ponto é preciso lembrar a Lei Estadual $\mathrm{n}^{\circ}$. 5.301, de 16 de setembro de 1986, que regulamentou a obrigatoriedade da previsão do espaço físico para a biblioteca nos projetos arquitetônicos das unidades escolares, a partir da data de sua assinatura. Antes disso, não havia um dispositivo legal que regulamentasse a matéria, o que trazia como conseqüência situações diferenciadas quanto a este planejamento físico.

As condições ambientais também foram pesquisadas e verificou-se que os itens iluminação, ventilação e segurança receberam a qualificação entre "bom" e "ótimo". A segurança foi o item que recebeu a melhor avaliação e a iluminação, a pior. De maneira geral, a iluminação parece ser o fator ambiental com maior problema nas 88 bibliotecas escolares, conforme o percentual de avaliação anotando "péssimas condições" e o menor anotando "ótimas condições".

Em relação aos ambientes existentes nas bibliotecas escolares e em seu entorno, verificouse que as áreas mais comuns são: área de atendimento ao público (77.78\%), área de leitura, estudo e pesquisa $(83.33 \%$ ) e área para armazenamento do acervo $(94.44 \%)$. Tal resultado demonstra que a área para armazenamento das coleções é o ambiente mais comum entre todas as bibliotecas escolares. As demais áreas possuem percentuais entre 44.44 e 27.78 e referem-se à: administração, serviços internos, leitura infantil, leitura de periódicos e atividades audiovisuais. Os $44.44 \%$ de indicações relativas à área de leitura infantil demonstram uma preocupação em proporcionar um ambiente diferenciado para o público infantil e suas atividades de leitura.

A maioria das salas destinadas à biblioteca escolar (55.55\%), têm um espaço menor ou igual a $50 \mathrm{~m} 2$, o tamanho de uma sala de aula. Por outro lado, $16.67 \%$ delas possuem espaço maior, variando de 50 a $70 \mathrm{~m} 2.27 .78 \%$ das bibliotecas escolares possuem espaço mais privilegiado, com área física de 70 a $100 \mathrm{~m} 2$, as quais possuem maior número de ambientes internos. Com certeza, a área física maior proporciona melhor condição de instalação da biblioteca e de atendimento aos usuários no local.

\subsubsection{Mobiliário e Equipamento}

O mobiliário existente para os usuários é composto de mesas coletivas e cadeiras, com baixa incidência de mesas individuais de traba-

Inf.Inf., Londrina, v. 4, n. 2, p. 78-94, jul./dez. 1999 
lho.

De maneira geral, existe uma média de 17.27 cadeiras distribuídas em 3.05 mesas coletivas, o que dá média de 5.66 cadeiras por mesa coletiva. Mas, a situação individual de cada biblioteca é muito diversificada: existe biblioteca com 2 cadeiras e nenhuma mesa; outra com 1 mesa coletiva e 1 cadeira; outra com 55 cadeiras para 6 mesas coletivas, com média de 9 cadeiras por mesa. Este resultado parece demonstrar que a cultura escolar privilegia o trabalho em grupo na biblioteca, sem preocupar-se com o estudo individual ou que, pelas restrições de espaço físico, as mesas coletivas proporcionam mais lugares para se sentar com menor ocupação de área física.

O mobiliário para os funcionários, serviços e armazenamento do acervo é composto essencialmente de estantes, escrivaninha, cadeira e arquivo. Encontrou-se a média de 12.72 estantes por biblioteca, 1.22 escrivaninha por biblioteca, 1.61 cadeira para funcionários e 1.33 arquivo por biblioteca.

Assim, pelos resultados, visualizam-se bibliotecas com uma escrivaninha de trabalho, ao lado de um arquivo, com materiais armazenados em estantes e com mesas coletivas para os usuários.

Equipamentos praticamente inexistem nas bibliotecas escolares. $\mathrm{O}$ equipamento mais citado é a máquina de escrever, com 11 indicações, o que corresponde a uma média de 0.61 por unidade escolar, seguido de aparelho de som, com média de 0.33 . Os outros equipamentos, Inf.Inf., Londrina, v. 4, n. 2, p. 77-94, jul./dez. 1999 mimeógrafo, xerox, vídeocassete, televisão, retroprojetor, projetor de slides, possuem baixas indicações, de 1 a 4, e médias de 0.05 a 0.22 por unidade escolar.

Tal situação parece demonstrar que a existência de equipamentos na escola pública não está diretamente relacionada com a biblioteca escolar, inferindo-se que sua responsabilidade de aquisição, guarda e uso deve ser de outro setor interno.

\subsubsection{Caracterização dos usuários}

Verificou-se que a maioria das unidades escolares proporciona aos seus professores, funcionários, alunos e respectivos familiares, acesso livre à biblioteca. Apenas em uma unidade escolar o acesso é controlado e, em apenas outra, o acesso é fechado. O público externo tem acesso à biblioteca em apenas 5 unidades, ou seja, em $27.77 \%$ delas. $\mathrm{O}$ atendimento à comunidade interna e suas extensões familiares é característica da biblioteca das unidades da rede pública estadual de ensino, assim como o acesso livre.

A biblioteca escolar é essencialmente freqüentada pelos alunos de 1o. grau, com média de 3.44 , na medida em que a rede escolar possui maior número de unidades escolares e população escolar majoritária de 1o.grau. Os dados parecem indicar que, quando a unidade é de 10. e de 2o. graus, há uma equivalência de freqüência entre os alunos dos dois níveis de ensino, com alguma tendência de maior freqüência dos alunos de 1o. grau.

Os professores também são usuários fre- 
qüentes da biblioteca em todas as unidades pesquisadas, com média de 3.27; os funcionários, numa média de 2.88, também a utilizam, o que representa uma freqüência quase regular. $\mathrm{O}$ público externo, com média de 0.66 , raramente utiliza a biblioteca.

\subsubsection{Recursos informacionais}

A responsabilidade pela seleção do acervo ou dos materiais é da própria biblioteca, com $83.33 \%$ de indicações, mas a administração da escola também é responsável em $27.78 \%$ das unidades.

Também é responsável pela seleção do acervo uma instituição estadual, indicada em $33.33 \%$ das escolas, que provavelmente é a Fundação para o Desenvolvimento da Educação, órgão da administração estadual responsável pela implementação e desenvolvimento das bibliotecas escolares. Tal situação parece indicar que, além dos acervos recebidos do órgão, a unidade escolar incorpora outros itens informacionais em sua coleção, selecionados e adquiridos por outra fonte de recursos.

Também ficou clara a expressiva participação dos professores, através de sugestões ou consultas, com médias de 3.55 e 3.05. Também é significativa a participação dos alunos, com média de 2.16 de sugestões.

Por outro lado, as sugestões de funcionários, as consultas aos alunos, aos funcionários, a catálogos de editores e a especialistas são menos utilizadas como meios auxiliares de seleção.
Os principais critérios para a seleção e o desenvolvimento dos acervos das bibliotecas escolares são: a data de publicação do material, seu custo e seu autor, com médias de 4.11 e 3.11, respectivamente. Dessa forma, o principal critério é a atualização da informação do material, combinado com as referências de autoria e preço. Um item a ser incorporado parece aquele referente à qualidade e preço em equilíbrio.

De maneira geral, a principal forma de aquisição dos itens da biblioteca é a doação feita por pessoas físicas, com média de 2.77 e por instituições públicas / governamentais, com média de 2.55. Mas, a compra em editoras e distribuidores e em livrarias, com médias de 2.27 e 2.0, respectivamente, também é uma forma significativa de aquisição.

Os recursos financeiros utilizados para a aquisição são provenientes das Associações de Pais e Mestres das unidades escolares, com percentual de $77.78 \%$ das indicações. Apenas $33.33 \%$ dos recursos advêm de instituições governamentais. Pode-se afirmar que as compras efetuadas dependem quase que exclusivamente da participação financeira das famílias dos alunos.

Em 44.44\% das unidades não houve necessidade de realizar estudos de avaliação de coleções. Mas, quanto às restantes, os processos de avaliação realizados enfatizaram a necessidade de verificar o estado de conservação $(33.33 \%)$ e de remanejar documentos desatualizados (33.33\%). Mas, procurou-se verificar que materiais são mais manuseados no intuito de providenciar mais exemplares, de remanejar aqueles 
menos manueados e de descartar os desatualizados.

O item predominante em todas as bibliotecas é o livro, com média de 4.039 por escola, com quantidade mínima de 300 e máxima de 12.172. Depois dos livros, os materiais também existentes em todas as bibliotecas são os dicionários (média de 41.88) e os atlas (média de 38.22). Há também, em bom número, enciclopédias, com média de 9.94 por unidade.

Os demais materiais indicados - almanaques, periódicos, apostilas, trabalhos escolares, recortes de jornais e gibis - são encontrados mais em uma e menos em outras unidades escolares. As tipologias documentais não impressas também possuem desequilíbrio acentuado entre as bibliotecas, a não ser os globos, existentes em praticamente todas as unidades. Vale destacar a existência de acervos significativos de discos, fitas cassete, jogos e coleções geológicas/biológicas em algumas poucas unidades escolares.

A maior biblioteca escolar possui 13 tipos de documentos e um total de 12.538 itens. Mesmo as bibliotecas menores quanto ao acervo possuem variedade de documentos, o que demonstra preocupação na coleta de diferentes suportes de informação.

As coleções são de alguma forma organizadas, pois praticamente em $94.44 \%$ das bibliotecas realizam-se processos de tombamento, classificação e catalogação. Questiona-se tal índice em relação à catalogação, pois, pelo conhecimento da realidade da biblioteca escolar, de fato há uma preocupação com o registro ou inventário dos documentos e com sua organização física por área de conhecimento ou por classificação de assunto, mas a descrição bibliográfica demanda pessoal especializado, infelizmente, não disponível em todas as unidades escolares.

\subsubsection{Serviços e Produtos}

As bibliotecas escolares funcionam no horário matutino e vespertino, com média diária de quase 3 horas de atendimento em cada um destes turnos de funcionamento. Mas, deve-se ressaltar que o horário de atendimento varia de menos de uma hora a 4 horas.

No horário noturno, o funcionamento é muito mais restrito, com média geral de 1 hora diária de atendimento. Em 50\% das unidades escolares a biblioteca não funciona no período noturno e no restante a duração varia de menos de 1 a 4 horas de funcionamento. Constatou-se que em apenas duas unidades escolares a biblioteca atende aos sábados.

Em relação aos serviços de alerta, o mural é o serviço mais realizado, existente em $61.11 \%$ das bibliotecas, seguido de listas de novas aquisições, presentes em 55.55\% delas.

Os serviços de fornecimento de documentos são elencados e percebe-se que em 100\% das bibliotecas são permitidas as consultas e os empréstimos. Também deve ser considerado o percentual de 55.55 para a realização de levantamentos bibliográficos a pedido de seus usuários. Enquanto os serviços de empréstimo entre bibliotecas e xérox são oferecidos em apenas $11.11 \%$ das unidades. 
Atividades de animação cultural e de incentivo à leitura são pouquíssimas. A hora do conto é atividade realizada em $44.44 \%$ das bibliotecas, seguida de exposições, palestras e feiras, com $33.33 \%$ de indicações.

Para o treinamento dos usuários a maioria dos responsáveis pelas bibliotecas, $94.44 \%$, indicaram haver orientações informais. Também é considerável a realização de visitas orientadas, com $83.33 \%$ de indicações.

\section{CONCLUSÕES}

A pesquisa realizada resulta no seguinte diagnóstico da situação das bibliotecas escolares da rede estadual de ensino no Município de São Carlos :

1) A maioria está em atividade regular de funcionamento e as unidades em que a biblioteca está desativada apontam como motivo principal a falta de pessoal, além da desorganização do acervo e a falta de recursos físicos (espaço, mobiliário e equipamentos);

2) Nas unidades cujas bibliotecas estão desativadas o acervo é colocado à disposição dos professores e alunos para uso no local;

3) As bibliotecas escolares em atividade possuem praticamente um funcionário, em geral um Professor III, com formação universitária, que divide sua jornada de trabalho docente com o trabalho na biblioteca ou que ali trabalha por ser readaptado e não ter condições de saúde para o exercício regular da

8) A biblioteca escolar não dispõe de equipamentos próprios e, se dispuser de algum, este é uma máquina de escrever;

9) A biblioteca escolar é aberta aos alunos, professores, funcionários e respectivos familiares, com livre acesso às estantes, mas são os professores e alunos os usuários mais freqüentes;

10) A seleção do acervo ou dos materiais é de responsabilidade da própria biblioteca, com Inf.Inf., Londrina, v. 4, n. 2, p. 78-94, jul./dez. 1999 
participação expressiva dos professores através de sugestões de compra;

11) Os principais critérios de seleção são: a data de publicação, o preço e a autoria, o que equilibra qualidade e custo do item bibliográfico;

12) O principal meio de desenvolvimento do acervo é a doação por parte de pessoas físicas e de instituições governamentais, seguida da compra em editoras, distribuidores e livrarias, com recursos financeiros advindos da Associação de Pais e Mestres da unidade escolar;

13) O acervo documental é formado basicamente por livros, obras de referência (dicionários, enciclopédias e atlas) e um globo terrestre, existindo uma grande diferenciação quantitativa entre as bibliotecas em relação às tipologias documentais existentes;

14) Verifica-se em todas as bibliotecas uma variedade de tipologias documentais impressas e não impressas, o que demonstra a necessidade de diversos suportes para a informação educativa;

15) Os acervos existentes possuem algum tipo de organização física, em geral por áreas de conhecimento ou assunto, mas praticamente inexistem instrumentos de recuperação da informação;

16) As bibliotecas escolares funcionam nos turnos matutino e vespertino, com média de quase 3 horas de atendimento em cada tur- no. Metade delas atende também no horário noturno, mas por apenas uma hora em média;

17) Os principais serviços oferecidos são consultas e empréstimos domiciliares; como serviço de alerta, a utilização do mural é predominante;

18) Praticamente inexistem atividades de animação cultural e incentivo à leitura, mas existe preocupação com o uso da biblioteca, expressa por orientações informais e visitas orientadas.

\section{REFERÊNCIAS BIBLIOGRÁFICAS}

\section{AMERICAN LIBRARY ASSOCIATION.} Personnel Organization and procedure : a manual suggested for us in college and university libraries. Chicago : ALA, 1952.

CARVALHO, Doris de Queiroz. Bibliotecas escolares: manual de organização e funcionamento. Rio de Janeiro : FENAME, 1972.

FUNDAÇÃO PARA O DESENVOLVIMENTO DA EDUCAÇÃO. Proposta para implantação dos centros de informação e criação. São Paulo : FDE, 1992.

GALlER, Anne M. , COULTER, Joan M. La administración de las bibliotecas escolares. La Haya : IFLA Headquarters, 1991.

MACEDO, Neusa Dias de, SIQUEIRA, Idméa Semeghini Próspero. Subsídios para caracterização da biblioteca escolar. Revista Brasileira de Biblioteconomia e Documentação, São Paulo, v. 20, n. 1/4, p. 65-69, jan./dez. 1987. 


\section{Title}

ORGANIZAÇÃO DOS ESTADOS AMERICANOS. Modelo flexível para um sistema nacional de bibliotecas escolares. Brasília : Comissão Brasileira de Bibliotecas Públicas e Escolares / FEBAB, 1985.

SANDRONI, Laura Constância, MACHADO, Luiz Raul. A criança e o livro: guia prático de estímulo à leitura. São Paulo : Ática, 1986.

SILVA, Waldeck Carneiro da. Miséria da biblioteca escolar. São Paulo : Cortez, 1995.
Diagnosis of public school libraries in São Carlos

\section{Abstract}

In this study the characterization of public school libraries of secondary and high school levels in São Carlos (São Paulo State - Brazil) concerning physical, material and human resources, document files, services provided and users' community is presented, the data having been raised from a diagnostic research.

\section{Keywords}

Public school libraries - São Carlos. São Paulo State. Brazil.

\section{Título}

Diagnóstico de las bibliotecas escolares de la red estadual de enseñanza del municipio de São Carlos

\section{Resumen}

Caracterización de las bibliotecas de las escuelas estaduales de la enseñanza primaria y secundaria del minicipio de São Carlos en lo que se refiere a recursos fisicos, materiales y humanos, acervos documentales, servicios ofrecidos y comunidad de usuarios. A partir de una pesquisa-diagnóstico fueron colectadas informaciones sobre los tópicos aqui ya mencionados.

\section{Palabras-clave}

Bibliotecas escolar - Enseñanza pública estadual primaria y secundaria - São Carlos. Estado de São Paulo

Artigo recebido em: 20/11/98

\section{Elisabeth Marcia Martucci}

Mestre em Biblioteconomia - PUC/camp

Doutoranda em Educação - PPGE/UFSCar

Professor Assistente

Departamento de Ciência da Informação

Centro de Educação e Ciências Humanas

Universidade Federal de São Carlos

\section{Maria Regina Milani}

Aluna de graduação

Curso de Biblioteconomia e Ciência da Informação

Universidade Federal de São Carlos 